\title{
Correction to: Beat-the-wave evacuation mapping for tsunami hazards in Seaside, Oregon, USA
}

\author{
George R. Priest ${ }^{1} \cdot$ Laura L. Gabel $^{1} \cdot$ Nathan J. Wood $^{2} \cdot \operatorname{Ian}$ P. Madin ${ }^{3}$. \\ Rudie J. Watzig ${ }^{3}$
}

Published online: 11 January 2018

(C) This is a U.S. Government work and not under copyright protection in the US; foreign copyright protection may apply 2018

\section{Correction to: Nat Hazards (2016) 80:1031-1056 \\ https://doi.org/10.1007/s11069-015-2011-4}

Due to a procedural error in construction of Figs. 8 and 9, listed minimum speeds to beat the tsunami wave in areas of Seaside seaward of Neawanna Creek are too high. The two figures should be replaced by the new figures below. Also note that e-mail addresses for George Priest, Laura Stimely (now Laura Gabel), Ian Madin, and Rudie Watzig are updated in this erratum.

The original article can be found online at https://doi.org/10.1007/s11069-015-2011-4.

George R. Priest

grpriest@yahoo.com

Laura L. Gabel

laura.gabel@oregon.gov

Nathan J. Wood

nwood@usgs.gov

Ian P. Madin

Ian.Madin@oregon.gov

Rudie J. Watzig

Rudie.Watzig@oregon.gov

1 Oregon Department of Geology and Mineral Industries, Coastal Field Office, PO Box 1033, Newport, OR, USA

2 Western Geographic Science Center, US Geological Survey, 2130 SW 5th Avenue, Portland, OR, USA

3 Oregon Department of Geology and Mineral Industries, 800 NE Oregon Street, Suite 965, Portland, OR, USA 
None of the conclusions of the paper are modified, but the two following sentences in the Discussion should be slightly modified.

Original sentences:

If only seismically retrofitted bridges are intact, only adults with no mobility impairment would be able to evacuate seaward of the Necanicum River or the mouth of Neawanna Creek (Fig. 8). Any evacuation delay beyond that caused by the 3-5 min of seismic shaking expected for CSZ earthquake would require fast walk to running speeds to evacuate these same areas (Fig. 9).

Revised sentences:

If only seismically retrofitted bridges are intact, only adults with no mobility impairment would be able to evacuate many areas seaward of the Necanicum River or the mouth of Neawanna Creek (Fig. 8). Any evacuation delay beyond that caused by the $3-5 \mathrm{~min}$ of seismic shaking expected for CSZ earthquake greatly shrinks the area that could be evacuated by the mobility impaired (Fig. 9). 


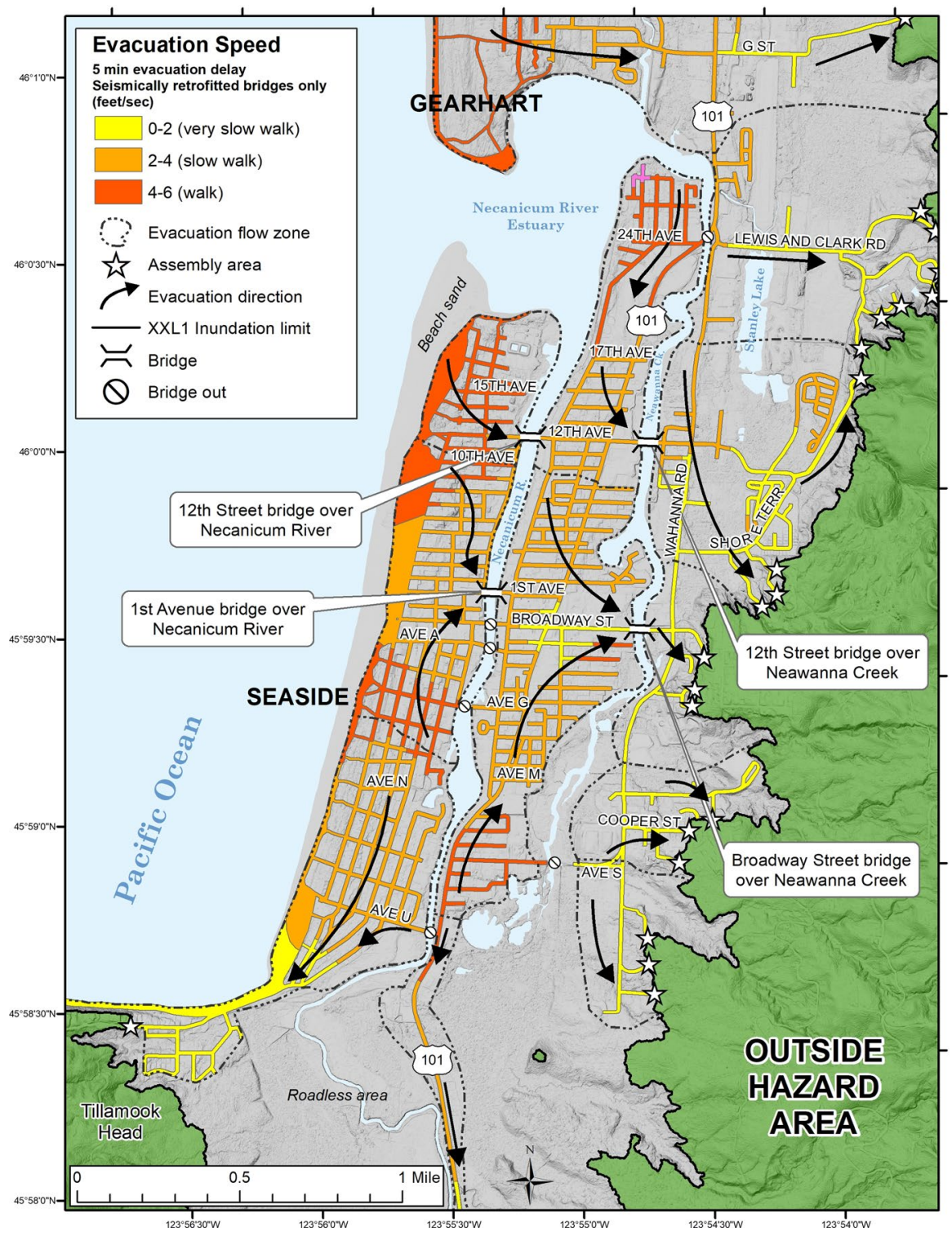

Fig. 8 Beat-the-wave (BTW) tsunami evacuation map of Seaside, Oregon, depicting minimum speeds to reach safety assuming a 5-min delay from beginning of the earthquake before evacuation can start but only retrofitted bridges intact. Arrival of the XXL1 scenario tsunami after the start of a Cascadia subduction zone earthquake varies across the map area from 20-21 min on the Necanicum River to 33-34 min at the inundation limit 


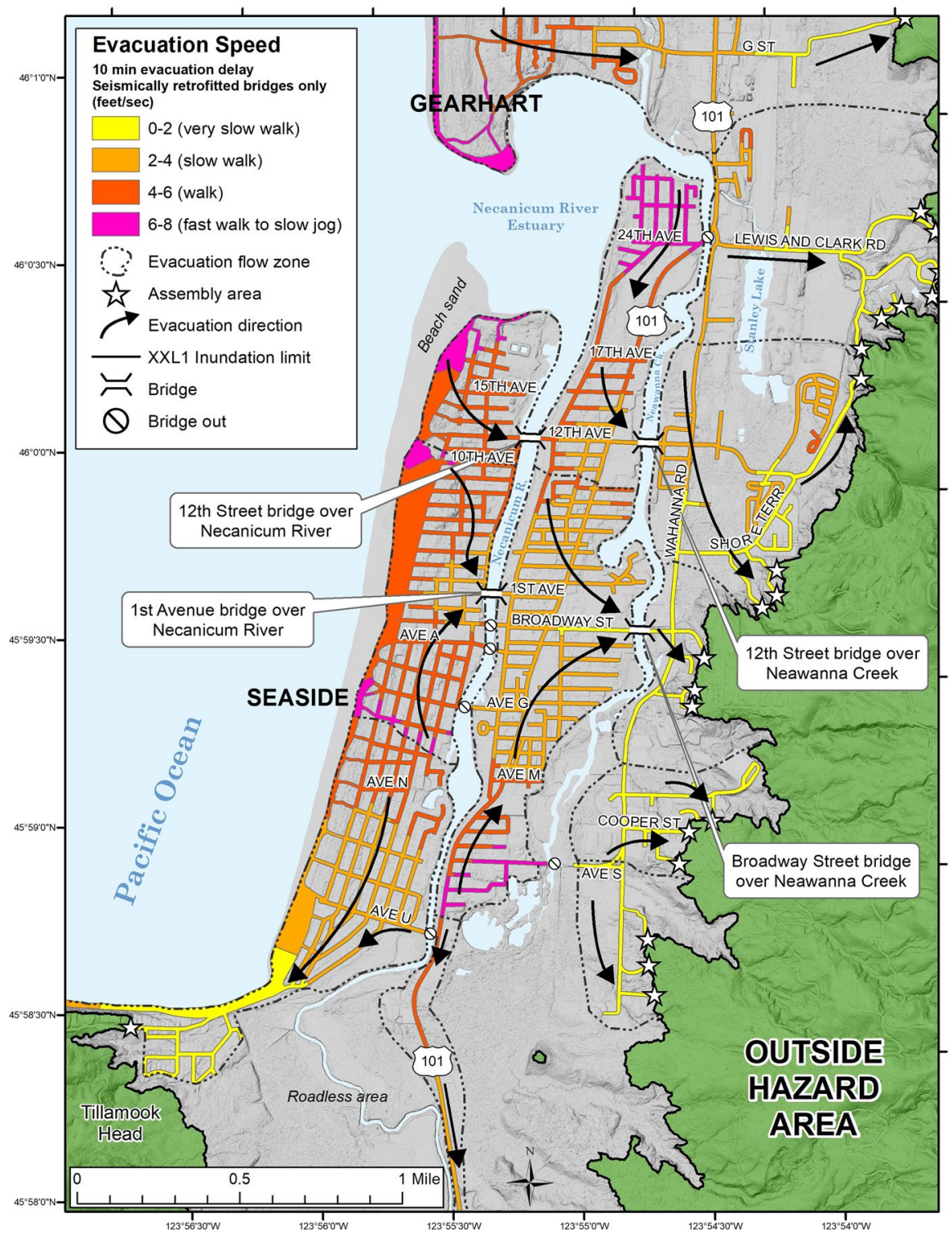

Fig. 9 Beat-the-wave (BTW) tsunami evacuation map of Seaside, Oregon, depicting minimum speeds to reach safety assuming a 10-min delay from beginning of the earthquake before evacuation can start but only retrofitted bridges intact. Arrival of the XXL1 scenario tsunami after the start of a Cascadia subduction zone earthquake varies across the map area from 20-21 min on the Necanicum River to 33-34 min at the inundation limit 